mansasa

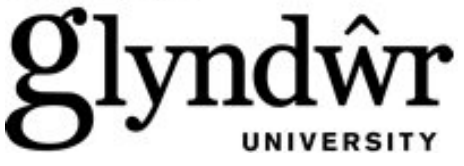

Glyndŵr University

Glyndŵr University Research Online

Aeronautical Engineering

Engineering

$12-1-2011$

\title{
The production of advanced fine-grained alumina by carbon nanotube addition
}

Fawad Inam

Glyndwr University, f.inam@glyndwr.ac.uk

Ton Peijs

University of London

Michael J. Reece

University of London

Follow this and additional works at: http://epubs.glyndwr.ac.uk/aer_eng

Part of the Aerospace Engineering Commons, Ceramic Materials Commons, Engineering $\underline{\text { Science and Materials Commons, and the Nanoscience and Nanotechnology Commons }}$

\section{Recommended Citation}

Inama, F., Peijs T., and Reece, M.J. (2011) 'The production of advanced fine-grained alumina by carbon nanotube addition'. Journal of the European Ceramic Society 31(15) 2853-2859

This Article is brought to you for free and open access by the Engineering at Glyndŵr University Research Online. It has been accepted for inclusion in Aeronautical Engineering by an authorized administrator of Glyndŵr University Research Online. For more information, please contact d.jepson@glyndwr.ac.uk. 


\title{
The production of advanced fine-grained alumina by carbon nanotube addition
}

\begin{abstract}
Alumina and alumina+1vol.\% carbon nanotube (CNT) composites were fully densified by spark plasma sintering. Post-sintering heat treatments $(1300-1500 \circ \mathrm{C})$ were performed to completely oxidize CNTs and then densify the remaining 1 vol.\% to produce fine-grained ceramics. The grain size and Vickers hardness of the heat-treated composites were compared with the monolithic alumina sintered without CNT addition. Compared to the initial powder particle size of alumina (D50: $356 \pm 74 \mathrm{~nm})$, minimal grain growth $(\sim 450 \mathrm{~nm})$ was observed for the fully dense heat-treated composites. A $25 \%$ improvement in Vickers hardness and $>10$ times finer average grain size were observed for alumina produced by the heat treatment $(1300 \circ \mathrm{C})$ of alumina+1vol.\% CNT composite, compared to alumina sintered without CNTs.
\end{abstract}

\section{Keywords}

SPS/FAST; Sintering; Grain growth; Grain size; Alumina; Carbon nanotubes; Hardness; Nanocomposite

\section{Disciplines}

Aerospace Engineering | Ceramic Materials | Engineering | Engineering Science and Materials | Nanoscience and Nanotechnology

\section{Comments}

Copyright (C) 2011 Elsevier Ltd. Published by Elsevier Ltd. All rights reserved. This is the author's final version of the work after peer review. The article was originally published in the Journal of the European Ceramic Society in 2011 by Elsevier. The full published article can be found at http://dx.doi.org/10.1016/

j.jeurceramsoc.2011.07.011 on the publisher's website http://www.sciencedirect.com/science/article/pii/ S0955221911003451 


\title{
The production of advanced fine-grained alumina by carbon nanotube addition
}

\author{
Fawad Inam*1, Ton Peijs ${ }^{1,2}$, Michael J. Reece ${ }^{1,2}$ \\ ${ }^{1}$ Glyndŵr University, Advanced Composite Training and Development Centre and School of \\ Mechanical and Aeronautical Engineering, Mold Road, LL11 2AW Wrexham, UK \\ ${ }^{2}$ Queen Mary University of London, School of Engineering and Materials Science, Mile End Road, \\ London E1 4NS, UK
}

\begin{abstract}
Alumina and alumina +1 vol.\% carbon nanotube (CNT) composites were fully densified by spark plasma sintering. Post-sintering heat treatments $\left(1300-1500{ }^{\circ} \mathrm{C}\right)$ were performed to completely oxidize CNTs and then densify the remaining 1 vol.\% to produce fine-grained ceramics. The grain size and Vickers hardness of the heat-treated composites were compared with the monolithic alumina sintered without CNT addition. Compared to the initial powder particle size of alumina $\left(\mathrm{D}_{50}: 356 \mathrm{~nm} \pm\right.$ $74 \mathrm{~nm})$, minimal grain growth $(\sim 450 \mathrm{~nm})$ was observed for the fully dense heat-treated composites. A $25 \%$ improvement in Vickers hardness and $>10$ times finer average grain size were observed for alumina produced by the heat treatment $\left(1300{ }^{\circ} \mathrm{C}\right)$ of alumina +1 vol.\% CNT composite, compared to alumina sintered without CNTs.
\end{abstract}

\section{Introduction}

Since Iijima's report [1], CNTs have been widely appreciated for producing advanced polymer [2,3], ceramic [4,5] and metal [6] composites. In the case of ceramic matrix composites (CMCs) [7], CNTs have been reported to improve the electrical conductivity [4,5], thermal conductivity [8], fracture strength [5] machinability [9], indentation fracture toughness [10], and contact damage resistance [11]. We recently reported that CNT addition significantly retards grain growth and lowers the full densification sintering temperature of polycrystalline CMCs [12]. The fine microstructure that this produces is advantageous improving mechanical properties. Hardness [13], strength [14], fatigue [15], wear [13], contact damage [16] and thermal shock resistance [17] increase with grain size refinement. Moreover, grain size reduction also improves the toughness of many alloys as well [18].

Owing to its good oxidation resistance, chemical stability and relatively high hardness, alumina (Al2O3) is one of the most widely used structural ceramic [19]. However, alumina-CNT composites are previously reported to have lower hardness as compared to monolithic alumina [10, 20-26] due to various reasons. Jiang et al. reported lower hardness and toughness for alumina +10 vol.\% CNT composite due to the degradation of CNTs during sintering [26]. An and Lim [20] reported poor dispersion of CNTs in alumina matrix was responsible for decreased hardness. Zhan et al. [10] and Laurent et al. [22] reported $21 \%$ and $43 \%$ decrease in hardness as compared to CNT-free ceramic matrices. The possible reasons presented by the authors were poor cohesion (between CNT and alumina grains) and graphitic (lubricating) nature of CNTs [10,22]. The presence of a relatively soft phase (hardness of multiwalled CNT in radial direction is 6-10 GPa [27]) at the grain boundaries of alumina eases the penetration of diamond indenter during Vickers indentation. This nullifies the effect of fine alumina grains produced by the presence of CNTs at the grain boundaries of the composite. Some papers have reported no effect [28] or improved hardness [5, 29-31] by the incorporation of CNTs. However, the improvements were marginal and no comments were presented on the interfacial interactions between hard ceramic particles and the lubricating CNTs. For instance, Mo et al. [29] and Burghard et al. [30] reported improvements of 6\% and 3\% respectively in the hardness values of CNT reinforced ceramic as compared to monolithics.

*Corresponding author. Tel no.: +44 1978 293938. Email address: f.inam@glyndwr.ac.uk (F. Inam) 
In this paper, CNTs were used for the first time to produce fine grained monolithic alumina. Alumina and alumina +1 vol. $\%$ composites were prepared by spark plasma sintering (SPS). CNTs have low oxidation resistance $\left(350-700{ }^{\circ} \mathrm{C}\right)$ [32]. After sintering, heat treatments $\left(1300-1500{ }^{\circ} \mathrm{C}\right)$ were performed to oxidise CNTs and densify the remaining 1 vol.\% porosity in the composites. The purpose of this paper is to exploit grain-size dominated properties, like hardness, by using CNTs as a grain growth suppressant in alumina matrix. The grain size and Vickers hardness of the heat-treated composites were compared with monolithic alumina sintered without CNT addition.

\section{Experimental}

\subsection{Starting materials}

The CNTs used in this study are commercially available as "multi-walled CNTs, NC-7000" from Nanocyl S.A., Belgium. They were synthesized by the catalytic CVD method and have an entangled cotton-like form. The CNTs have an average outer diameter of $9.5 \mathrm{~nm}$ (10 graphitic shells), lengths of up to 1.5 microns, purity of $\sim 90 \%$ and density of $1.66 \mathrm{~g} / \mathrm{cm}^{3}$. An acid treatment was performed using a mixture of nitric $\left(\mathrm{HNO}_{3}, 90 \%\right)$ and sulfuric $\left(\mathrm{H}_{2} \mathrm{SO}_{4}, 90 \%\right)$ acids. Distilled water ( 20 vol.\%) was used to dilute the acids. In order to produce pure CNTs, the as-received CNTs (400 mg) were mixed with $200 \mathrm{ml}$ acidic solution. Both acids were equally mixed in the solution. The acid-CNT mixture was homogenized by stirring with a glass rod on heating plate $\left(\sim 85{ }^{\circ} \mathrm{C}\right)$ for $30 \mathrm{~min}$ and then bath ultrasonicated for $2 \mathrm{hrs}$. The resulting CNT dispersion was thoroughly washed with distilled water until the filtrate was colorless and neutral $(\mathrm{pH} \sim 7)$ after filtration. A Whatman filter paper of $1 \mu \mathrm{m}$ was used. The purified CNTs were then dried for $48 \mathrm{hrs}$ at $100{ }^{\circ} \mathrm{C}$ in an oven. CNTs were purified to $>98 \%$ by acid treatment. The alumina powder used in this study is commercially available as "AKP 53 aluminum oxide" micro-powder from Sumitomo, Japan. As supplied, the main features of this product are: alpha phase; purity: $99.99 \%$; BET surface area $11.7 \mathrm{~m} / \mathrm{g}$; melting point $2050{ }^{\circ} \mathrm{C}$; and density 3.97 $\mathrm{g} / \mathrm{cm}^{3}$. Particle size analysis of alumina was performed using Malvern nanozeta sizer.

\subsection{Powder preparation}

Alumina +1 vol.\% (0.42 wt.\%) CNT composites were prepared. The CNTs were dispersed in DMF [33] via high power bath sonication for $2 \mathrm{hrs}$ and then hand mixed with alumina powder for another 5 min. The liquid mixture was transferred to another nylon jar filled with zirconia balls (milling media) of two different sizes (10 and $5 \mathrm{~mm}$, mass ratio: 3:2). The jar was sealed and rotation ball milled for 6 hrs at $\sim 200 \mathrm{rpm}$. The milled slurry mixture was dried at $100{ }^{\circ} \mathrm{C}$ for $5 \mathrm{hrs}$ in a rotary evaporator in the presence of $5 \mathrm{~mm}$ zirconia balls to avoid re-aggregation of CNTs [33]. The dried power was than dried in an oven $\left(85{ }^{\circ} \mathrm{C}\right)$ for $24 \mathrm{hrs}$ for complete removal of DMF. After drying, the powder was sieved in a $250 \mu \mathrm{m}$ stainless steel sieve. The same procedure was used for monolithic alumina powder.

\subsection{Sintering}

SPS is a rapid [34] and CNT-friendly [35] manufacturing technique that allows lower sintering temperatures and shorter dwell durations. Dried composite powder $(\sim 4 \mathrm{~g})$ was poured into a carbon die (diameter $20 \mathrm{~mm}$ ) and cold pressed at 1 ton for $5 \mathrm{~s}$ before sintering. Composite discs ( 3 $\mathrm{mm}$ thick) were prepared by SPS in an HPD 25/1 furnace (FCT Systeme, Germany). The sintering rate was 100 ${ }^{\circ} \mathrm{C} / \mathrm{min}$ and sintering temperature was $1450{ }^{\circ} \mathrm{C}$. A pressure of $100 \mathrm{MPa}$ was applied in the range 1100$1200{ }^{\circ} \mathrm{C}$ and released at the end of the sintering time, which was $5 \mathrm{~min}$. The furnace has a pyrometer focused on a hole close to the sample in the upper punch to measure the processing temperature. The same sintering procedure was repeated for the monolithic alumina powder for the sake of consistency in this comparative study. It should be noted that these sintering conditions were selected after systematic analysis (results not included).

\subsection{Heat treatments and characterizations}

The sintered samples were ground using $\mathrm{SiC}$ paper and diamond polished down to $1 \mu \mathrm{m}$. Density measurements were conducted using water buoyancy (archimedes) method and helium pycnometery. All polished samples were oxidized and thermally etched in a single run. Diffused carbon and CNTs were oxidized at $700{ }^{\circ} \mathrm{C}$ for $3 \mathrm{hrs}$ in a Carbolite HTF 1800 furnace and then heat treated/ thermally etched in the range $1300-1500{ }^{\circ} \mathrm{C}$ for $1 \mathrm{hr}$. The heating and cooling rate was $3{ }^{\circ} \mathrm{C} / \mathrm{min}$. Sintered samples were also fractured in order to observe the grain size. Fractured and thermally etched polished surfaces were gold coated and observed in a SEM (FEI, Inspect F, $20 \mathrm{kV}$ ). Grain sizes were measured 
according to ASTM E112 (line-fraction method) with the aid of the software (Image tool, v3, developed by UTSHCSA, USA). A minimum of 500 readings was taken to measure the grain sizes of each material. Vickers hardness was evaluated in accordance with ASTM C1327-03 [36]. Load of $1 \mathrm{~kg}$ was used for a duration time of $15 \mathrm{sec}$ and at least 10 measurements were averaged.

\section{Results and Discussion}

\subsection{Pre-heat treatment analysis}

Figure 1 shows alumina particle size and shape of the as supplied powder. The particles appear to be roughly spherical and of the dimensions $200-500 \mathrm{~nm}$. From particle size analysis, $\mathrm{D}_{50}$ was found to be $356 \mathrm{~nm} \pm 74 \mathrm{~nm}$. The common sintering temperature $\left(1450{ }^{\circ} \mathrm{C}\right)$ used in this study was the minimum temperature required for full densification of alumina and/ or alumina + CNT composite. Figure 2 shows fully-densified alumina and alumina +1 vol. $\%$ CNT composite. The grain size of the alumina $(4.86 \pm 0.81 \mu \mathrm{m})$ is much coarser than that of the alumina +1 vol.\% CNT composite $(0.39 \pm 0.19 \mu \mathrm{m}$, figure 2). In previous work, the effect of carbon black (CB) on densification and grain growth was also studied [12]. As compared to $\mathrm{CB}$, CNTs significant refine final grain size of alumina and a much lower sintering temperature is required for full-densification of alumina composite [12]. Higher magnification analysis of alumina (figure $2 b$ ) shows very fine porosity on the grains. It is very difficult to eliminate such porosity during rapid sintering as used in the present study. Such features were not observed for the alumina +1 vol.\% CNT composite (figure $2 \mathrm{~d}$ ). Figure $2 \mathrm{~d}$ also shows individual and homogenously dispersed CNTs in the alumina matrix. This is consistent with our previous work where CNTs were located at the grain boundaries and retard grain coarsening by reducing their mobility during sintering [12]. Therefore, homogenous dispersion of CNT is crucial for achieving narrow grain size distribution in the final heat treated alumina.

Mean measured hardness of alumina and alumina +1 vol.\% CNT composite was found to be $17.3 \mathrm{GPa}$ and 16.5 GPa respectively. Lower hardness was observed for alumina +1 vol.\% CNT composite as compared to monolithic alumina (prior to heat treatment). This can also be estimated by using the hardness rule-of-mixture equation for composites [37]:

$$
H_{C}=H_{M}\left(1-V_{F}\right)+H_{F} V_{F} \quad \text { Equation } 1
$$

Where, $H_{C}=$ hardness of composite, $H_{M}=$ intrinsic hardness of the matrix phase, $V_{F}=$ volume fraction of the filler phase and $H_{F}=$ intrinsic hardness of the filler phase. The experimentally measured hardness of alumina $+1 \mathrm{vol} . \%$ CNT composite $(16.5 \mathrm{GPa})$ was found to be less than the theoretically predicted value of $17.1 \mathrm{GPa}$ (hardness of multiwalled CNT in radial direction 6-10 GPa [27]). Equation 1 is a useful tool for approximation and does not consider the effect of interfacial strength, dispersion, orientation, aspect ratio and crystallinity of CNTs on the hardness of composite. CNTs lower the hardness of the composite despite it having a $>10$ times finer grained microstructure as compared to alumina (figure 2), due to their graphitic (lubricating) nature and poor cohesion with alumina grains [10, 22]. In comparison, ceramic dopants [38] and CNTs [12] suppress grain growth and improve the sinterability of alumina, their effect on the mechanical properties is quite different. For instance, there is no difference in hardness between an undoped alumina and the $\mathrm{MgO} / \mathrm{Y}_{2} \mathrm{O}_{3}$ doped (500 ppm) alumina [38].

\subsection{Post-heat treatment analysis}

To achieve the benefits of fine grained microstructure produced by the incorporation of CNTs in alumina, suitable heat treatments $\left(1300-1400{ }^{\circ} \mathrm{C}\right.$ ) were carried out (table 1). Figure 3 shows polished surfaces of heat-treated samples. The selected heat treatments (table 1) were used for three reasons: a) to fully oxidise CNTs at $700{ }^{\circ} \mathrm{C}(3 \mathrm{hrs})$ to produce monolithic alumina; b) to fully-densify alumina after oxidation of the CNTs, which left 1 vol.\% porosity; and b) to thermally etch the polished surface for revealing grain boundaries. No CNTs or diffused carbonaceous impurities were observed during microscopic analysis of the fracture surfaces of heat-treated composites. The colour of all composite samples also changed from bluish black to pearl white after heat-treatments. Therefore it is concluded that CNTs were thoroughly oxidized after heat-treating them at $700{ }^{\circ} \mathrm{C}(3 \mathrm{hrs})$ and the carbon was removed from the samples. 
Owing to the enormous aspect ratio of CNTs, very low volume of CNTs $(<0.8$ vol.\%) is required to make inherently insulting alumina conductive [39]. CNTs offer conductive paths in alumina composite and such percolative networks also provide a diffusion path during the oxidation of the CNTs. The remaining porosity is connected, which makes it easy to eliminate as compared to isolated porosity in alumina (figure $2 \mathrm{~b}$ ). During post sintering heat-treatment, grain coarsening and densification may occur depending on the temperature [40]. It was found that the heat-treatments used here densified the minor residual porosity $(\sim 1 \mathrm{vol} . \%)$ left by the oxidation of CNTs (table 1$)$. For instance, heattreatments $\left(1400{ }^{\circ} \mathrm{C}\right.$ and $\left.1500{ }^{\circ} \mathrm{C}\right)$ of the composites produced fully-dense monolithic alumina.

The heat-treatments increased the grain size and thermally etched the polished surfaces (figure 3 ). The driving force for grain growth is inversely proportional to the size of the grains [41]. Therefore the thermal etching is not recommended for the observation of fine grained ceramics. However, a big difference in grain size was still observed between heat-treated alumina and alumina +1 vol.\% CNT composites (figure 3). For example, alumina (figure $3 \mathrm{a}$ ) and alumina +1 vol. $\%$ CNT composite (figure 3d), heat-treated at $1300{ }^{\circ} \mathrm{C}$, have similar densities but the difference in their grain size is $>10$, i.e. alumina: $4.91 \mu \mathrm{m}$ and heat-treated alumina +1 vol.\% CNT composite: $0.40 \mu \mathrm{m}$.

The fine grained monolithic alumina produced by the heat-treatment of the composite has improved Vickers hardness as compared to heat-treated alumina sintered without CNT addition (table 1, figure 4). For monolithic polycrystalline ceramics, the grain dependence of hardness arises primarily from its impact on plastic deformation, which is the primary mechanism of forming permanent indentations [37]. In classical grain boundary strengthening theory $[18,37]$, the grain boundaries act as pinning points and impede dislocation movement across grains. Impeding such dislocation movement hinders the onset of plasticity and make fine grained materials stronger and harder [18, 42]. This can be estimated theoretically by the well-known Hall-Petch (HP) relation [43,44]. Valid at low temperatures and for grains sizes $>\sim 10 \mathrm{~nm}$ [45], it describes the relationship between hardness and grain size of the polycrystalline ceramics.

\section{$\boldsymbol{H}=\boldsymbol{H}_{\boldsymbol{R}}+\boldsymbol{k d}^{-1 / 2} \quad$ Equation 2}

where $H$ is the measured hardness by Vickers indentation, $H_{R}$ is the reference hardness, $k$ is a proportionality constant (Petch parameter) and $d$ is the mean grain size. The relation was originally developed for yield strength but it is also valid for hardness [37]. As compared to heat-treated alumina sintered without CNTs, improvement in the hardness was observed for the heat-treated composites (table 1). For example, hardness of composite and alumina heat-treated at $1300{ }^{\circ} \mathrm{C}$ was found to be 21.3 and $17 \mathrm{GPa}$, respectively (figure 4). It should also be noted that the residual stresses generated during rapid sintering of samples were relieved during slow post-sintering heat-treatments (heating/ cooling rate: $2{ }^{\circ} \mathrm{C} / \mathrm{min}$ ). The improved hardness in heat treated composites is solely due to the refinement in grain size and improved density. It is not due to the presence of residual compressive stresses as reported by Jian et al. [26].

In heat-treated $\left(1300{ }^{\circ} \mathrm{C} / 1 \mathrm{hr}\right)$ composite sample, the final grain size is almost the same as initial powder particle size. Such results were previously only possible when very high pressures (1-8 GPa) were used during the sintering of alumina [46-49]. For example, Liao et al. [49] applied $8 \mathrm{GPa}$ pressure during conventional lengthy sintering process to produce a microstructure having a mean grain size of $50 \mathrm{~nm}$ using $18 \mathrm{~nm}$ starting powder alumina. Here, only $100 \mathrm{MPa}$ in combination with CNTs were used during SPS to produce a significant microstructural refinement in alumina, resulting increase in hardness. The current strategy of producing fine ceramics is also relatively fast and up scalable. Chen and Wang presented a two-step method to produce fine monolithic ceramic [50]. However, the final dwell times were $20-40 \mathrm{hrs}$ and the grain size was $>4$ times larger as compared to initial powder particle size. The process may not industrial friendly because of its high energy utilization. A higher grain size difference is achieved in current study and the total processing time is much shorter (total dwell times: $<5 \mathrm{hrs}$ ) as compared to Chen and Wang's two step method [50]. 


\section{Conclusion}

CNTs are useful for improving the properties of advanced CMCs [4,5, 7-11], they can also be used to produce fine monolithic ceramics, as presented for the first time in this paper. In ceramic - CNT composites, hardness depends more on the presence of lubricating CNTs at the grain boundaries than on fine grain size. Owing to physical (large aspect ratio, low percolative and fibrous nature) and chemical (low oxidation resistance) properties of CNTs, advanced fine-grained polycrystalline alumina were produced by a two-step method. Heat treatments at $1400{ }^{\circ} \mathrm{C}$ and $1500{ }^{\circ} \mathrm{C}$ oxidized CNTs thoroughly and densified the remaining 1 vol.\% porosity. The average grain size in heat-treated composite, which is monolithic alumina, was found to be $>10$ times finer than that of alumina sintered without CNT addition. A 25\% improvement in Vickers hardness was measured for monolithic alumina produced after the heat treatment of alumina +1 vol.\% CNT composite, as compared to monolithic alumina sintered without CNTs. The final grain size in heat-treated composite was almost the same as the starting powders. This method uses less energy as a result of reduced pressure and processing times as compared to previously researched methods [46-49]. Characterization of other grain-size dependant properties and utilization of direct electrical heating to oxidise CNTs in composites will be the subjects of future research.

\section{References}

[1] Iiima S. Helical microtubules of graphitic carbon. Nature 1991;354(6348):56-8.

[2] Inam F, Wong DYW, Kuwata M, Peijs T. Multiscale hybrid micro-nanocomposites based on carbon nanotubes and carbon fibers. J Nanomater 2010; DOI: 10.1155/2010/453420.

[3] Wang Z, Ciselli P, Peijs T. The extraordinary reinforcing efficiency of single-walled carbon nanotubes in oriented poly(vinyl alcohol) tapes. Nanotechnology 2007;18(45):455709.

[4] Inam F, Yan H, Jayaseelan DD, Peijs T, Reece MJ. Electrically conductive alumina - carbon nanocomposites prepared by spark plasma sintering. J Eur Ceram Soc 2010;30(2):153-7.

[5] Peigney A, Garcia FL, Estournès C, Weibel A, Laurent C. Toughening and hardening in doublewalled carbon nanotube/ nanostructured magnesia composites. Carbon 2010;48(7):1952-60.

[6] Kwon H, Estili M, Takagi K, Miyazaki T, Kawasaki A. Combination of hot extrusion and spark plasma sintering for producing carbon nanotube reinforced aluminum matrix composites. Carbon 2009;47(3):570-7.

[7] Cho J, Boccaccini AR, Shaffer MSP. Sintering ceramic matrix composites containing carbon nanotubes. J Mater Sci 2009;44(8):1934-51.

[8] Sivakumar R, Guo S, Nishimura T, Kagawa Y. Thermal conductivity in multi-wall carbon nanotube/ silica-based nanocomposites. Scr Mater 2007;56(4):265-8.

[9] Wan Y, Kim DW, Jang JS, Park YB. Micro electro discharge machining of CNT-based nanocomposite materials. Inter Mech Eng Cong Expos. Seattle (Washington, USA): ASME, 2007;p. $409-13$.

[10] Zhan GD, Kuntz JD, Wan J, Mukherjee AK. Single-wall carbon nanotubes as attractive toughening agents in alumina-based nanocomposites. Nat Mater 2003;2(1):38-42.

[11] Wang XT, Padture NP, Tanaka H. Contact-damage-resistant ceramic/single-wall carbon nanotubes and ceramic/graphite composites. Nat Mater 2004;3(8):539-44.

[12] Inam F, Yan HX, Peijs T, Reece MJ. The sintering and grain growth behaviour of ceramic-carbon nanotube nanocomposites. Compos Sci Technol 2010; 70(6):947-52.

[13] Xu HHK, Jahanmir S. Effect of grain size on scratch damage and hardness of alumina. J Mater Sci Lett 1995;14(10):736-9.

[14] Miyahara N, Yamaishi K, Mutoh Y, Uematsu K, Inoue M. Effect of grain size on strength and fracture toughness in alumina. JSME Inter J Ser A 1994;37(3):231-7.

[15] Li M, Reece MJ. Influence of grain size on the indentation-fatigue behaviour of alumina. J Am Ceram Soc 2000;83(4):967-70.

[16] Guiberteau F, Padture NP, Lawn BR. Effect of grain size on Hertzian contact damage in alumina. J Am Ceram Soc 1994;77(7):1825-31.

[17] You XQ, Si TZ, Liu N, Ren PP, Xu YD, Feng JP. Effect of grain size on thermal shock resistance of $\mathrm{Al}_{2} \mathrm{O}_{3}-\mathrm{TiC}$ ceramics. Ceram Int 2005;31(1):33-8.

[18] Callister WD. Materials science and engineering; an introduction, 5th ed. New York: John Wiley \& Sons;2000. 
[19] Okada A. Automotive and industrial applications of structural ceramics in Japan. J Eur Ceram Soc 2008; 28(5):1097-1104.

[20] An JW, Lim DS. Effect of carbon nanotube additions on the microstructure of hot-pressed alumina. J Ceram Process Res 2002;3(3):201-4.

[21] Sun J, Gao L, Iwasa M, Nakayama T, Niihara K. Failure investigation of carbon nanotube/3YTZP nanocomposites. Ceram Inter 2005;31(8):1131-4.

[22] Laurent C, Peigney A, Dumortier O, Rousset A. Carbon nanotubes-Fe-alumina nanocomposites. Part II: microstructure and mechanical properties of the hot-Pressed composites. J Eur Ceram Soc 1998;18(14):2005-13.

[23] Balazsi C, Shen Z, Konya Z, Kasztovszky Z, Weber F, Vertesy Z, et al. Processing of carbon nanotube reinforced silicon nitride composites by spark plasma sintering. Compos Sci Technol 2005;65(5):727-33.

[24] Boccaccini AR, Thomas BJC, Brusatin G, Colombo P. Mechanical and electrical properties of hot-pressed borosilicate glass matrix composites containing multi-wall carbon nanotubes. J Mater Sci 2007;42(6):2030-6.

[25] Thomson KE, Jiang D, Lemberg JA, Koester KJ, Ritchie RO, Mukherjee AK. In situ bend testing of niobium-reinforced alumina nanocomposites with and without single-walled carbon nanotubes. Mater Sci Eng A 2008;493(1-2):256-60.

[26] Jiang D, Thomson K, Kuntz JD, Agerb JW, Mukherjee AK. Effect of sintering temperature on a single-wall carbon nanotube-toughened alumina-based nanocomposite. Scr Mater 2007;56(7):959-62.

[27] Zhu C, Guo W, Yu TX, Woo CH. Radial compression of carbon nanotubes: deformation and damage, super-elasticity and super-hardness. Nanotechnology 2005;16(8):1035-9.

[28] Ahmad K, Pan W. Hybrid nanocomposites: a new route towards tougher alumina ceramics. Compos Sci Technol;68(6):1321-7.

[29] Mo CB, Cha SI, Kim KT, Lee KH, Hong SH. Fabrication of carbon nanotube reinforced alumina matrix nanocomposite by sol-gel process. Mater Sci Eng A 2005;395(1-2):124-8.

[30] Burghard Z, Schon D, Garstel P, Bill J, Aldinger F. Polymer-derived Si-C-N ceramics reinforced by single-wall carbon nanotubes. Int J Mater Res 2006;97(12):1667-72.

[31] Cha SI, Kim KT, Lee KH, Mo CB, Hong SH. Strengthening and toughening of carbon nanotube reinforced alumina nanocomposite fabricated by molecular level mixing process. Scr Mater 2005;53(7):793-7.

[32] Frank B, Rinaldi A, Blume R, Schlogl R, Su DS. Oxidation stability of multiwalled carbon nanotubes for catalytic application. Chem Mater 2010;22(15):4462-70.

[33] Inam F, Yan HX, Reece MJ, Peijs T. Dimethylformamide: an effective dispersant for making ceramic - carbon nanotube composites. Nanotechnology 2008;19(19):195710.

[34] Olevsky EA, Kandukuri S, Froyen L. Consolidation enhancement in spark-plasma sintering: impact of high heating rates. J Appl Phys 2007;102(11):114913.

[35] Inam F, Yan HX, Reece MJ, Peijs T. Structural and chemical stability of multiwall carbon nanotubes in sintered ceramic nanocomposite. Adv Appl Ceram 2010;104(4):240-5.

[36] ASTM C 1327-03. Standard test method for Vickers indentation hardness of advanced ceramics 2003.

[37] Rice RW. Mechanical properties of ceramics and composites - grain and particle effects. New York: Marcel Dekker;2003.

[38] Hah SR, Fischer TE, Gruffel P, Carry C. Effect of grain boundary dopants and mean grain size on tribomechanical behavior of highly purified $\alpha$-alumina in the mild wear regime. Wear 1996;1813(1):165-77.

[39] Ahmad K, Pan W, Shi SL. Electrical conductivity and dielectric properties of multiwalled carbon nanotube and alumina composites. Appl Phys Lett 2006;89(13):133122.

[40] Chen RZ, Tuan WH. Thermal etching of alumina. Am Ceram Soc Bull 2000;79(10):83-6.

[41] Kingery WD, Bowen HK, Uhlmann DR. Introduction to ceramics. 2nd ed. New York: Wiley Interscience; 1976.

[42] Schaffer JP, Saxena A, Antolovich SD, Sanders TH, Warner SB. The science and design of engineering materials. Chicago: R.D. Irwin; 1995.

[43] Hall EO. The deformation and ageing of mild steel: III discussion of results. Proc. Phys. Soc. B 1951;64(9):747-53.

[44] Petch NJ. The cleavage strength of polycrystals. J Iron Steel Inst 1953;174(1):25-8. 
[45] Hansen N. Boundary strengthening over five length scales. Adv Eng Mater 2005;7(9):815-21. [46] Mishra RS, Lesher CE, Mukherjee AK. High-pressure sintering of nanocrystalline $\gamma$ Al2O3. J Am Ceram Soc 1996;79(11):2989-92.

[47] Gallas MR, Rosa AR, Costa TH, da Jornada JAH. High pressure compaction of nanosize ceramic powders. J Mater Res 1997;12(3):764-8.

[48] Gonzalez EJ, Hockey B, Piermarini GJ. High pressure compaction and sintering of nano-size $\gamma$ $\mathrm{Al}_{2} \mathrm{O}_{3}$ powder. Mater Manu Process 1996;11(6):951-67.

[49] Liao SC, Chen YJ, Kear BH, Mayo WE. High pressure/ low temperature sintering of nanocrystalline alumina. Nanostruct Mater 1998;10(6):1063-79.

[50] Chen IW, Wang XH. Sintering dense nanocrystalline ceramics without final-stage grain growth. Nature 2000;404(6774):168-71.

\section{Figures and table}

Table 1. Summary of samples analyzed in this study.

\section{Sample}

Alumina
Alumina
Alumina
Alumina
Alumina + 1 vol.\% CNT
Alumina + 1 vol.\% CNT
Alumina + 1 vol.\% CNT
Alumina + 1 vol.\% CNT
Alumina + 1 vol.\% CNT

$$
\text { Heat treatment }
$$

Density

Grain size

$99.7 \quad 4.86 \pm 0.81 \mu \mathrm{m}$

$99.9 \quad 4.91 \pm 0.41 \mu \mathrm{m}$

$99.9 \quad 5.04 \pm 0.35 \mu \mathrm{m}$

$99.9 \quad 5.29 \pm 0.31 \mu \mathrm{m}$

99.9

$0.39 \pm 0.19 \mu \mathrm{m}$

98.9

$0.40 \pm 0.12 \mu \mathrm{m}$

$99.8 \quad 0.45 \pm 0.11 \mu \mathrm{m}$

99.9

$0.75 \pm 0.16 \mu \mathrm{m}$

99.9
Hardness

$17.3 \pm 0.9 \mathrm{GPa}$

$17.0 \pm 0.9 \mathrm{GPa}$

$700{ }^{\circ} \mathrm{C} / 3 \mathrm{hr}, 1300{ }^{\circ} \mathrm{C} / 1 \mathrm{hr}$

$700{ }^{\circ} \mathrm{C} / 3 \mathrm{hr}, 1400{ }^{\circ} \mathrm{C} / 1 \mathrm{hr}$

$700{ }^{\circ} \mathrm{C} / 3 \mathrm{hr}, 1500{ }^{\circ} \mathrm{C} / 1 \mathrm{hr}$
$1.08 \pm 0.19 \mu \mathrm{m}$

$18.8 \pm 0.5 \mathrm{GPa}$

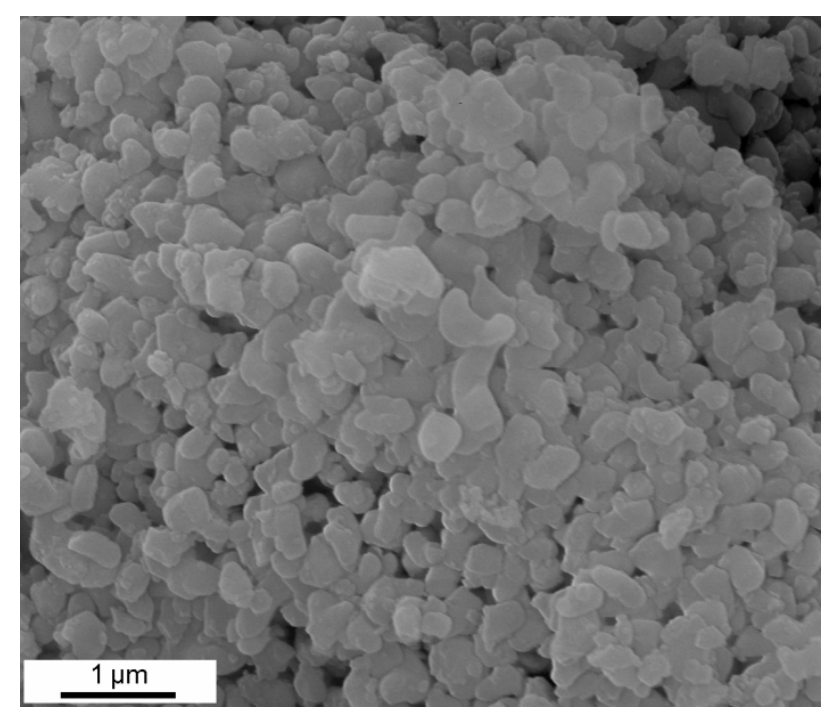

Figure 1. Raw alumina powder $\left(D_{50}: 356 \mathrm{~nm} \pm 74 \mathrm{~nm}\right)$. 

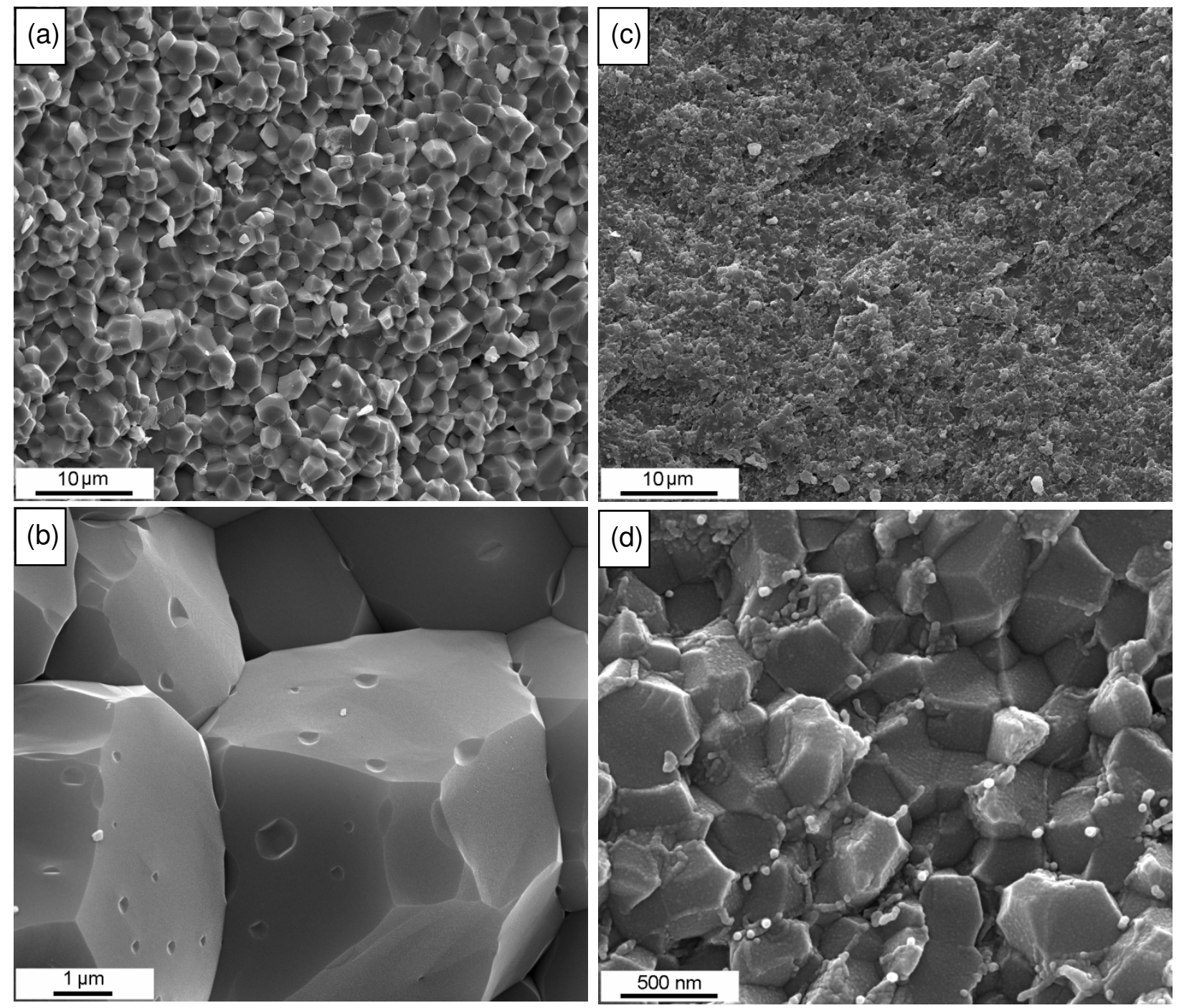

Figure 2. Fractured surfaces of fully densified materials prior to heat treatments. SPSed at $1450{ }^{\circ} \mathrm{C} /$ $100 \mathrm{MPa} / 5 \mathrm{~min}$. Alumina at: a) low magnification; b) high magnification. Alumina + 1 vol.\% CNT composite at: c) low magnification; and d) high magnification. 


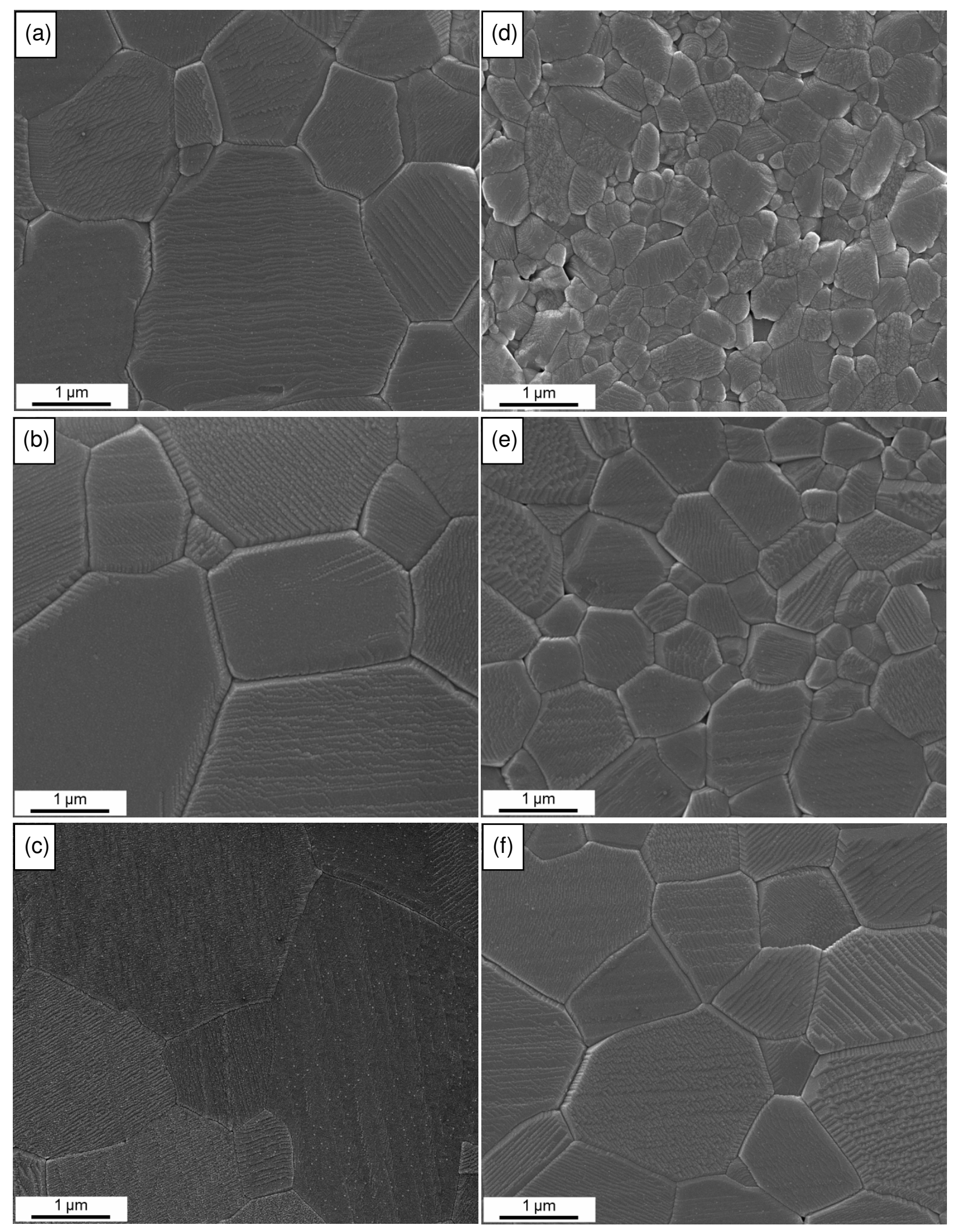

Figure 3. Polished and heat treated samples, alumina: a) $1300{ }^{\circ} \mathrm{C}$; b) $1400{ }^{\circ} \mathrm{C}$ and c) $1500{ }^{\circ} \mathrm{C}$, alumina +1 vol. $\%$ CNT composite: d) $1300{ }^{\circ} \mathrm{C}$; e) $1400{ }^{\circ} \mathrm{C}$ and f) $1500{ }^{\circ} \mathrm{C}$. 


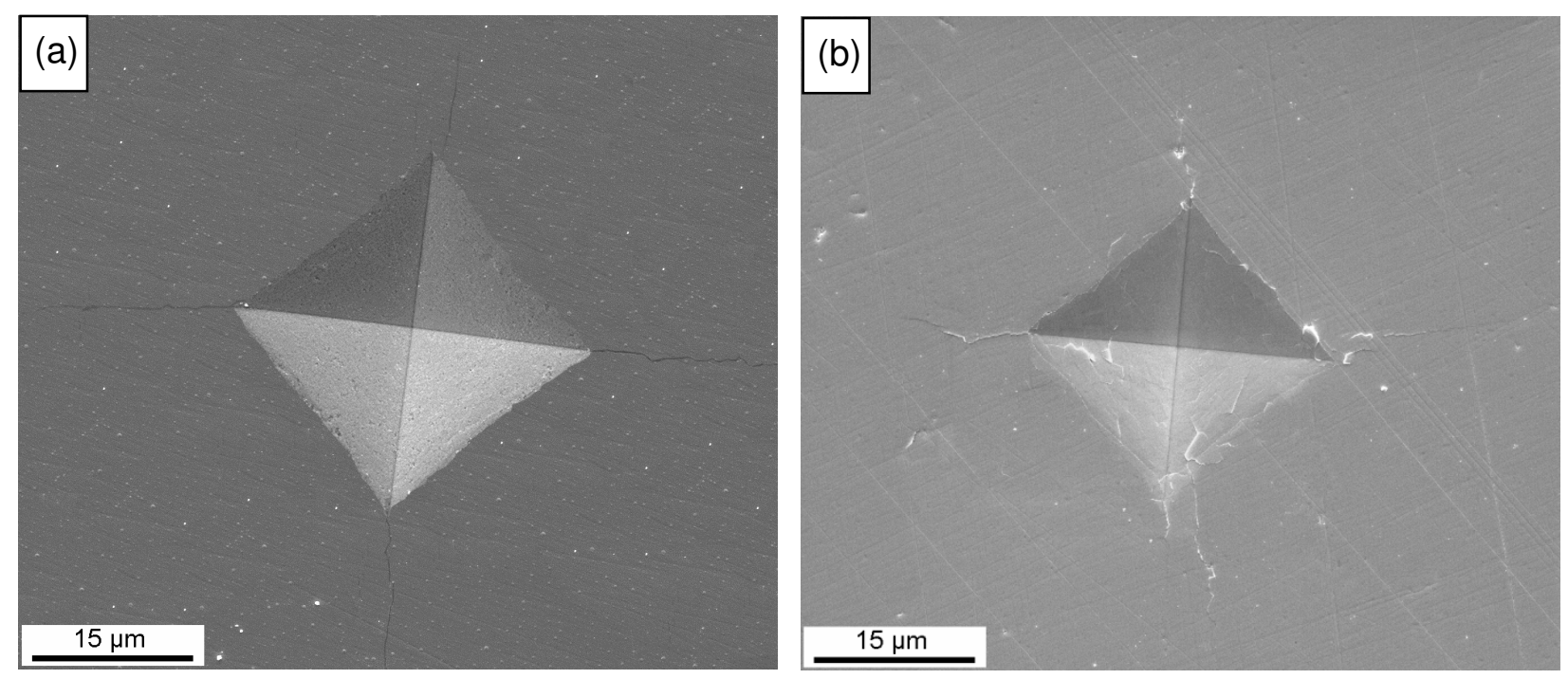

Figure 4 . Vickers indent by $1 \mathrm{~kg}$ loading. Samples heat-treated at $700{ }^{\circ} \mathrm{C}(3 \mathrm{hrs})$ and $1300{ }^{\circ} \mathrm{C}(1 \mathrm{hr})$ : a) alumina sintered with CNT addition (diagonal length: $33.75 \mu \mathrm{m}$ ); and b) alumina sintered with CNT (diagonal length: $29.11 \mu \mathrm{m}$ ). 